\title{
APPLICATION OF AN INTEGRATED APPROACH TO STUDY FLOODING IN COASTAL AREAS
}

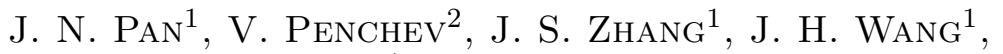 \\ D. Dragancheva ${ }^{3 *}$, M. J. Xiong ${ }^{1}$, F. PencheV ${ }^{2}$, \\ D. T. WANG ${ }^{1}$ AND S. Shukrieva ${ }^{2}$ \\ ${ }^{1}$ Nanjing Hydraulic Research Institute, \\ 223, Guangzhou Road, Nanjing 210024, P. R. China, \\ e-mails: jnpan@nhri.cn; jszhang@nhri.cn; jhwang@nhri.cn; \\ e-mails: mjxiong@nhri.cn; dtwang@nhri.cn \\ ${ }^{2}$ Black Sea Danube Association for Research and Development, \\ 1, William Froude St., Engineering Block "B", 9003 Varna, Bulgaria, \\ e-mails: v.penchev@bdcabg.org; f.penchev@bdcabg.org; \\ e-mail: s.shukrieva@bdcabg.org \\ ${ }^{3}$ Institute of Metal Science, Equipment and Technologies \\ with Hydro- and Aerodynamics Centre "Acad. Angel Balevski", \\ Bulgarian Academy of Sciences, \\ 1, William Froude St., 9003 Varna, Bulgaria, \\ e-mail: d.dragancheva@bshc.bg
}

\section{The present paper is dedicated to the $45^{\text {th }}$ anniversary of the Bulgarian Ship Hydrodynamics Centre in Varna}

\begin{abstract}
Based on an analysis on the available tools for simulation of coastal flooding in urban and estuarine area an integrated approach is demonstrated, focused on the use of advanced numerical modeling tools, verified by large scale physical model tests, and data from coastal oceanography surveys. Two different numerical tools have been tested for various flood events in urbanized coastal areas with high risk of compound flooding. Flood inundation has been simulated for various scenarios for urbanized coastal area, Bulgaria, and parameters of wave overtopping for the protective dike of Beilun city, China, have been calculated under combined action of sea-level variations and waves. The numerical results can be used to assist flood risk assessment and contribute to environmentally sound solutions for protection of coastal and riverside cities against compound flooding.
\end{abstract}

Keywords: digital elevation model, field data, numerical simulations, model verification, physical model tests.

\footnotetext{
*Corresponding author.

DOI: 10.7546/EngSci.LVIII.21.03.01
} 


\section{INTRODUCTION}

The integrated modelling, which unites physical modelling, numerical simulations, and verification with field measurement data, gives a reliable approach to improve modelling and achieve a reliable prediction of inundation in floodplain areas at different scenarios of the initial conditions. The numerical modelling of flooding and other flood-related processes in coastal and riverside areas with complex topography, bathymetry and morphology frequently requires significant efforts to build a detailed digital elevation model, as well as further model optimisation, in order to achieve useful conclusions. Physical model tests should be carried out at a large enough scale to minimise the scale effects, and concentrating on important processes that are not well enough understood to be modelled accurately in a numerical model, i.e. interactions of short-scale and long-scale processes. The results of model tests are analysed to increase process understanding of the behaviour of the system but are also parameterised so that they can be incorporated into a numerical model that covers a wider area.

The elements of integrated modelling can essentially complement each other - physical model provides verification data for numerical models; numerical simulations and lab tests provide the continuum information to bridge the gaps in field data. In addition, numerical modelling can also be used for the design of the physical model and to overcome its limitations, as well allows initial assessment of the conditions which must be reproduced in the laboratory experiment. A detailed analysis of the possibilities, strengths and weaknesses of physical and numerical models is presented in [1].

Integrated modelling approach is applicable for assessment of coastal flooding processes due to storm surges, wave action, tide, overtopping, breaches, as well as for flash floods and river overflow due to excessive rainfall over an extended period, but most of all - for the worst combination of these natural phenomena in coastal and estuarine areas. It should be noted that a single modelling tool cannot adequately reproduce the complex processes involved in flooding problems, and thus replace all the others. Different modelling tools add value, but also add cost. Therefore it needs to consider in advance how many physical and numerical models and field measurements can complement each other, and then decide if it matters to invest to combine them. In addition, care must be taken to not transfer or multiply errors or scale effects from one model to another [2].

The objective of the present study is to test and discuss two cases of integrated modeling and respectively the using of two different tools for numerical simulation of coastal flooding in urban and estuarine area in coastal region 
of Bulgaria, and overtopping of coastal dike under combined effect of storm surge and waves in coastal region of P. R. China.

\section{CASE STUDY I: ASPARUHOVO-KARANTINA COASTAL AREA (BLACK SEA, BULGARIA)}

Asparuhovo-Karantina is urbanized coastal area near Varna, Bulgaria, Fig. 1. It is located in the southern part of Varna Bay on the western coast of the Black Sea (a closed sea, with negligible tidal variations). The residential area includes a sandy beach, actively used by tourists in summer season. The study area includes also a fishing harbor and a small river (gulley) next to it, whose design layout was used in the study. This area, being at low elevation above the sea level, was already flooded in a flash flood in 2014, and is therefore considered with moderate to high risk of flooding.
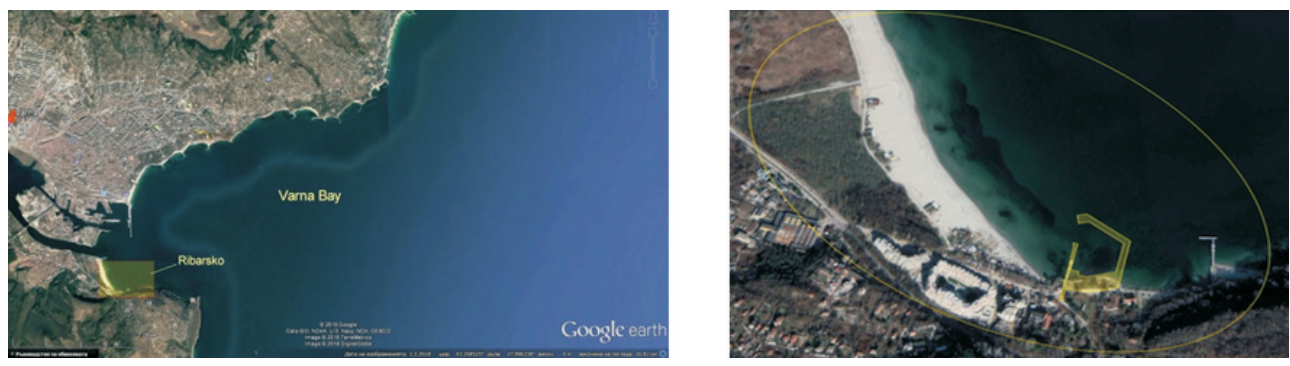

Fig. 1. Case study area near Varna, Bulgaria

\subsection{Terrain and bathymetry data}

Detailed field measurements were carried out to collect field data necessary to build an accurate Digital Elevation Model (DEM) of Karantina area, including terrain of land with buildings and infrastructure in the urbanized area. The DEM was created with a spatial resolution of $(1 \times 1) \mathrm{m}$ in plan, and $15 \mathrm{~cm}$ in vertical on the base of data from hydrographic measurements and terrain scanning. Terrain and bathymetry data were integrated in a GIS environment, and used to generate a 3D surface map on the base of standard triangulation techniques.

\subsection{Numerical modelling by MIKE 21}

From wide range of models in MIKE Software family, developed by Danish Hydraulic Institute and released during more than 30 years, numerical models 
MIKE FLOOD, MIKE 21 Spectral Wave (SW) and MIKE 21 Boussinesq Wave (BW) were used in this study.

MIKE FLOOD is flexible software with the possibility to integrate 1D (MIKE 11) and 2D (MIKE $21 \mathrm{FM} / \mathrm{HD}$ ) models and perform more complex hydrodynamic simulations by different combinations between the $1 \mathrm{D}$ and $2 \mathrm{D}$ model.

MIKE $21 \mathrm{SW}$ is a state-of-the-art third generation spectral wind-wave model that simulates the growth, decay and transformation of wind-generated waves and swells in offshore and coastal areas. It includes two different formulations: A fully spectral formulation and a directional decoupled formulation. The first formulation is based on the wave action conservation equation and the second one is based on a parameterization of the wave action conservation equation. MIKE $21 \mathrm{SW}$ is mainly used for simultaneous wave analysis on regional and local scale. A coarse mesh and large time steps are employed for the regional scale, while a high resolution boundary and depth-adaptive mesh are used for the shallow water areas.

Several data sets were combined in the process of the generation of the unstructured computational mesh for the simulations with MIKE $21 \mathrm{SW}$ of Asparuhovo-Karantina beach area. The generated meshes are illustrated in Fig. 2 ( $\mathrm{a}, \mathrm{b})$.

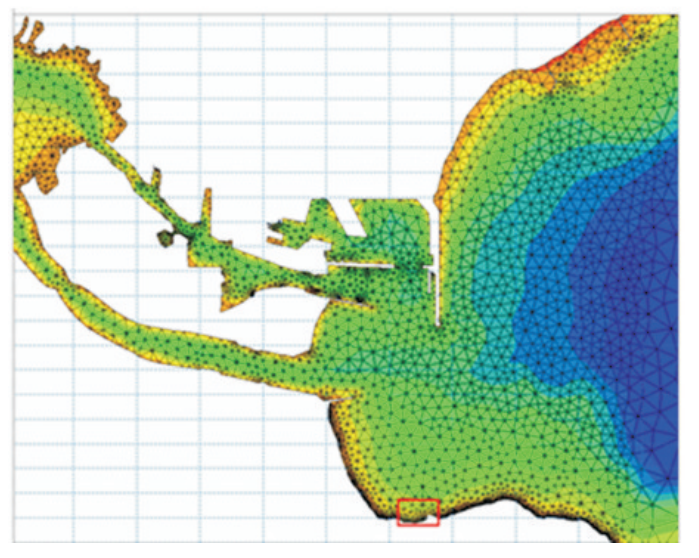

(a)

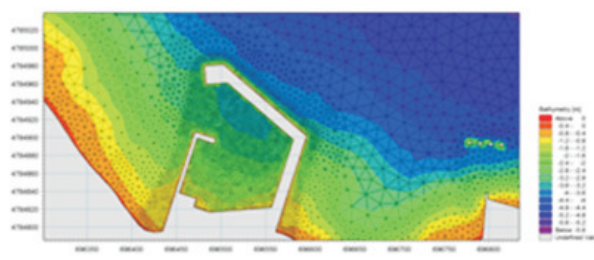

(b)

Fig. 2. Unstructured flexible mesh for MIKE SW simulations:

(a) Varna bay; (b) Asparuhovo beach area and fishing harbor Karantina

A MIKE SW model was applied to evaluate waves entering shallow water, and provide boundary conditions for a MIKE $21 \mathrm{BW}$ model to study wave diffraction/transformation in the nearshore zone and in the harbor area. 
The numerical model simulation results from MIKE $21 \mathrm{SW}$ model were compared with water level (storm surge) and wave data for the shallow water and wave breaking zone of the Asparuhovo beach area provided from Institute of Oceanology, BAS [3].

On the basis of the numerical bathymetry and the prepared meshes for the SW model, an additional numerical model has been set up with a higher resolution for the Karantina area in order to construct the final model for the simulations of combined flooding, including spill of the river combined with rising sea level driven by a storm. The described high resolution Digital Elevation Model (DEM) in the area of the river, harbor and beach is illustrated in Fig. 3.

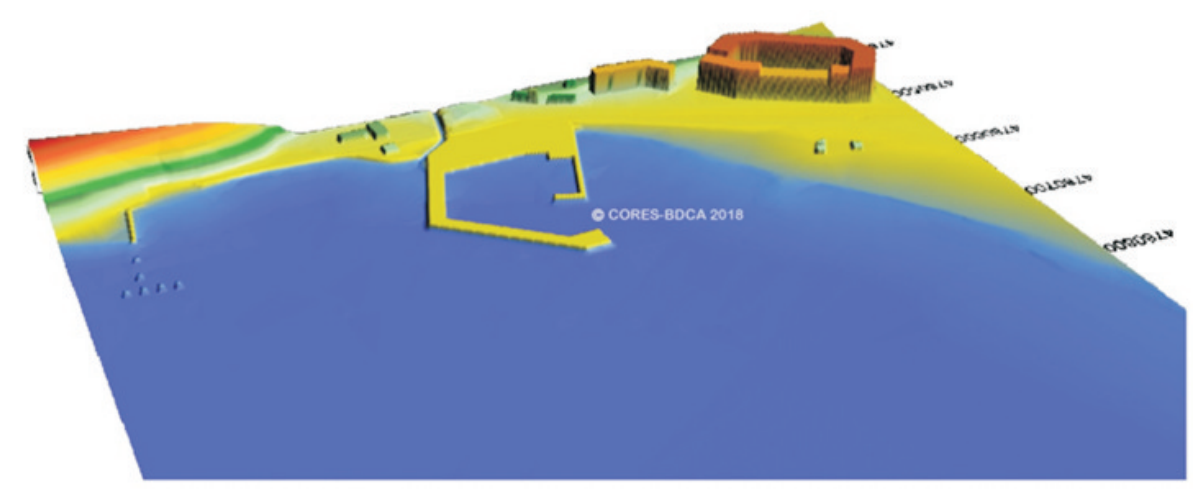

Fig. 3. 3D Visualization of the DEM of the Asparuhovo beach and residential area, including sea bathymetry, sand beach, terrain, roads, buildings, fishing harbor and a small river

A MIKE FLOOD model was used to study riverine flow in the small river (1D approach), followed by a 2D MIKE $21 \mathrm{FM}$ model, integrating both sea level elevation (coastal flooding) and the fluvial flood (river overflow). The calculation mesh comprises of 500000 finite elements. Bed resistance is varying in the domain, higher values close to the beach and lower values offshore.

For numerical simulation of the inundation in the case study area a gradual increase in the mean sea level was simulated to levels typical of extreme meteorological events with a very long return period, and which levels are quite significant in terms of beach flooding and overtopping the new harbor and coastal infrastructure.

A combination with multi-year river discharge was added to try to estimate compound flooding. Results of the simulations in the high-resolution DEM of the study area are illustrated in Fig. 4. 

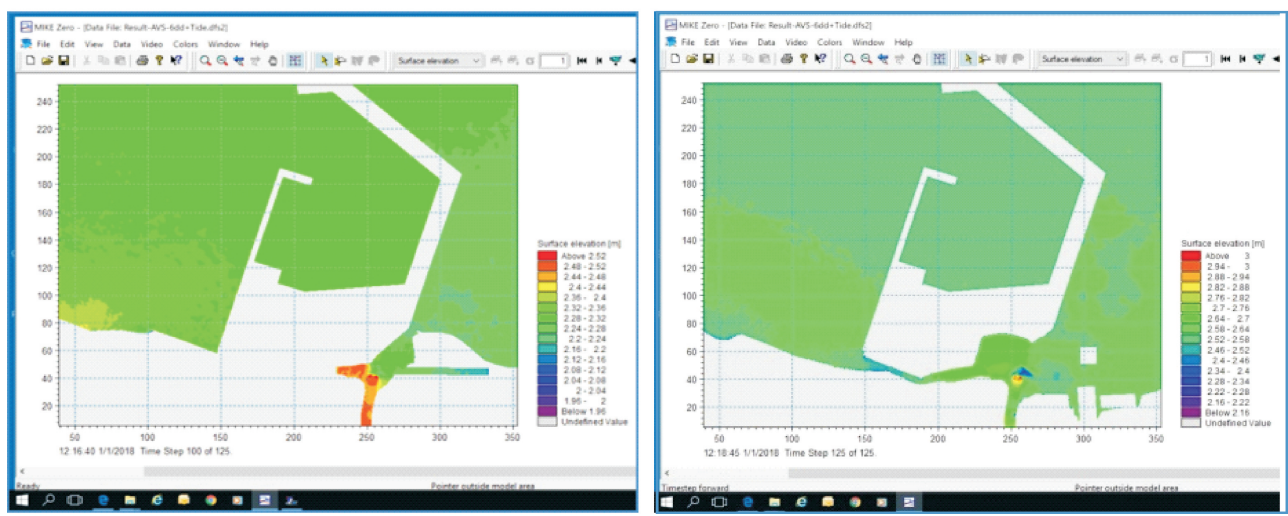

Fig. 4. Example results of tests by MIKE FLOOD model of compound coastal and fluvial flooding in Asparuhovo-Karantina area

(Sea level rise and water coming from the small river)

\section{CASE STUDY II: PROTECTIVE DIKE AT BEILUN COAST (CHINA)}

The study area is located at Beilun coast in Ningbo, Zhejiang province, which is severely affected by storm surge disasters along the west coast of the Chinese Sea, Fig. 5.

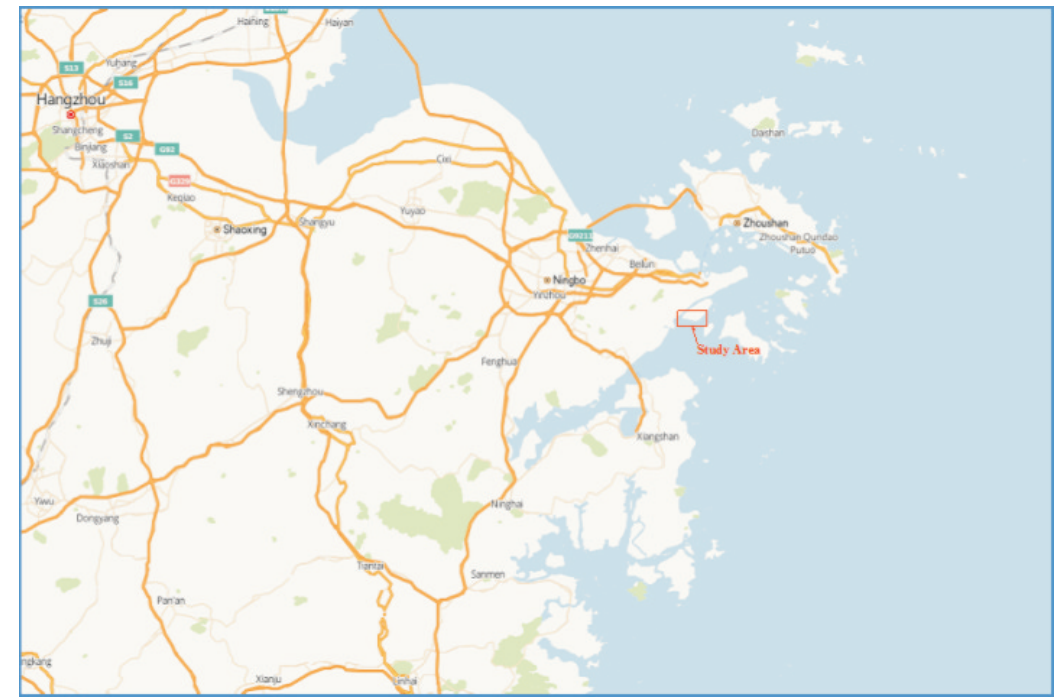

Fig. 5. Case study area near Beilun city, China 
Prediction of wave overtopping of existing coastal structures is an important requirement when assessing the risk of coastal floods. At present, the mean rate of wave overtopping for a particular coastal structure is commonly estimated with empirical formulae or by detailed physical model tests. The physical model results are restricted to specific wave conditions, specific geometries and structure characteristics related to the laboratory or prototype configurations.

Modern tide-wave-surge coupled numerical model uses the wave simulated by the phase-averaged wave model, which is based on a spectral energy balance equation. However, the phase averaged wave model has a strong limitation in the nearshore areas, especially when interacting with a structure like sea dike.

\subsection{Physical model}

The physical model experiment of overtopping was conducted for the dike engineering of Beilun, Fig. 6, to simulate the dynamic process of the combined action of storm surges, waves and tides; the geometric scale of the model was set at 1:16.
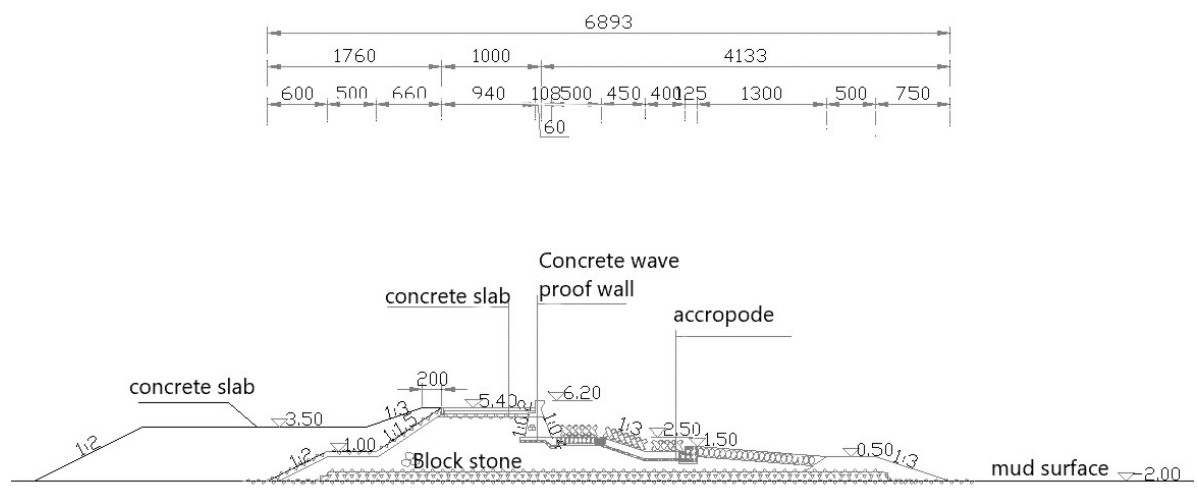

Fig. 6. Typical seawall cross-section in Beilun, Ningbo

Wave and tidal coupling simulation was carried out in the long wave flume $(175 \times 1.2 \times 1.8) \mathrm{m}$ of State key laboratory of hydrology-water resource and hydraulic engineering in Nanjing Hydraulic Research Institute (NHRI), Fig. 7. The working section of the flume is divided into two parts each $0.6 \mathrm{~m}$ wide. The one part is used to place the model section and conduct model test, and the other part is used for diffusing the secondary reflection wave of the wave making plate. The flume is equipped with a gentle slope for dissipating waves on one end, and with a push-plate irregular wave generator produced 
by NHRI on the other end, which is automatically controlled by the computer to generate wave elements requiring simulation. The wave making system can produce regular and irregular waves of different spectrum. The wave height was measured by a DS30 capacitive wave height meter, which collects and records the wave data by computer, collecting box and corresponding software. The ZWS-40 intelligent water level tracker is used to measure dynamic water level.

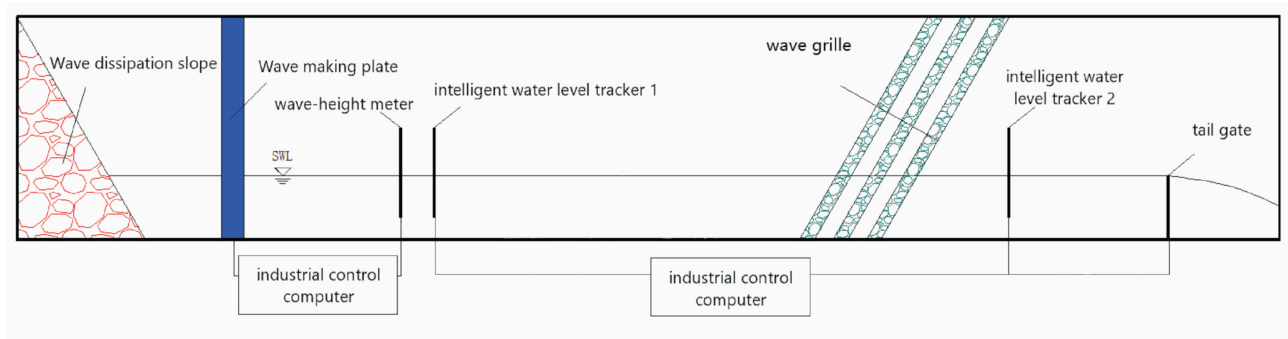

Fig. 7. A schematic diagram of the wave flume

The simulated waves and storm surge were reproduced from the registered data of Typhoon Winnie, No. 9711, which induced the most severe storm surge in Ningbo area for 1/100 years. Figure 8 shows the water level changes of storm surge, significant wave height and mean wave period during 4 days of typhoon Winnie in the region of the engineering site. The red frame range in Fig. 8 is the selected time period for simulation during the model tests.

In order to simulate the combined effect of storm surges and waves, the flume was modified to simulate tidal level change by controlling the tail gate height to adjust the variation of water level. During the experiment the wave maker and tide generator generated synchronous waves and storm surge. Figure 9 illustrates the superposed water level process of waves and storm surge.

\subsection{Numerical modelling by SWASH}

In recent years, advances in numerical methods and computer hardware have enabled the implementation of the Reynolds-average Navier-Stokes equations (RANS) to simulate the wave overflow of impervious seawalls by implementing Euler (VOF) or Lagrangian free surface tracking ( $\mathrm{SPH}$ ) techniques. Although the RANS model shows good agreement with the physical model results of the wave overtopping, these models require advanced numerical simulation techniques to achieve computational intensification or shortening the computational time. On the other hand, the models based on the Nonlinear 


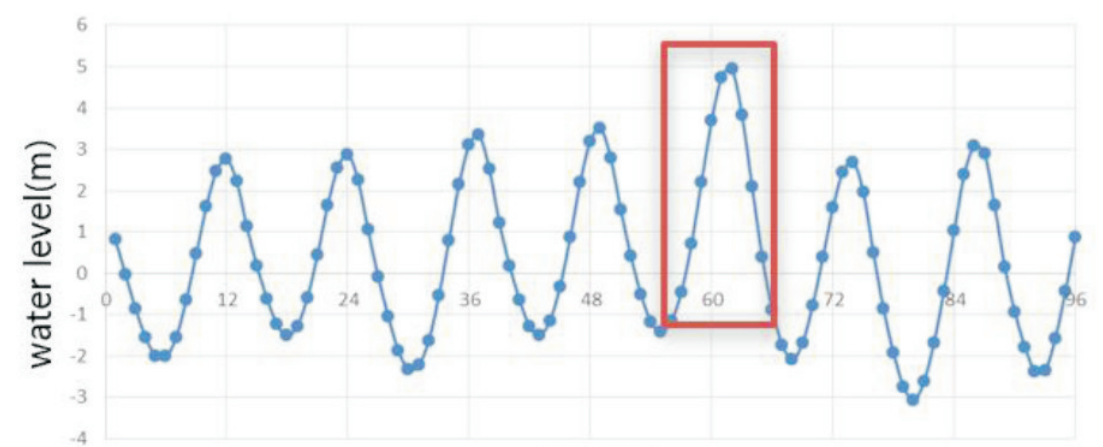

Time(h)

(a)

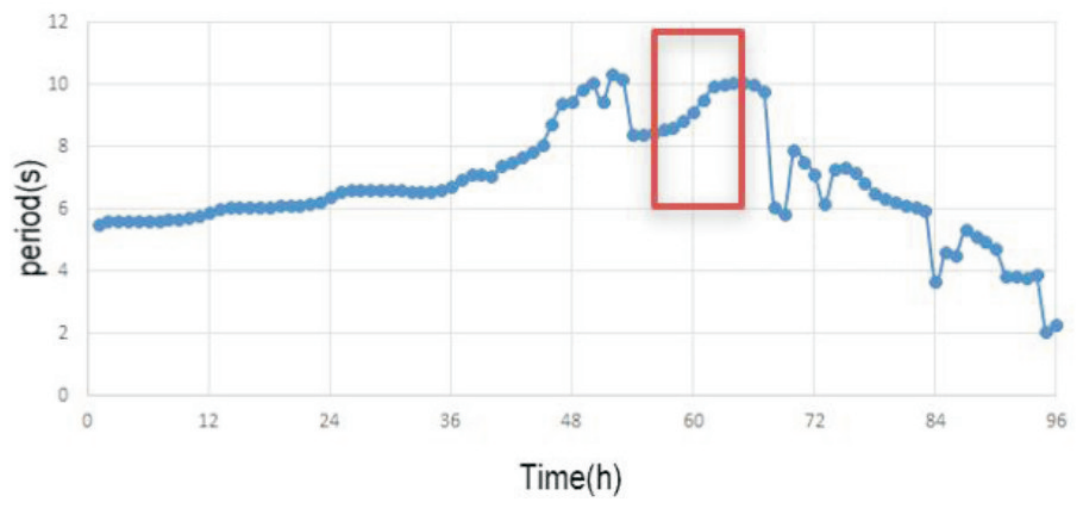

(b)

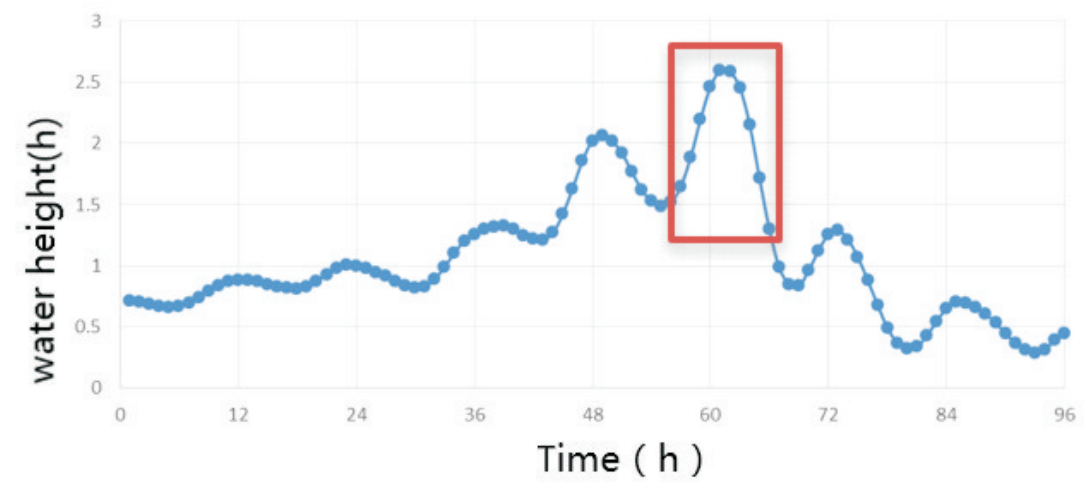

(c)

Fig. 8. (a) Water level, m; (b) wave period, s;

(c) wave height, $\mathrm{m}$, during typhoon Winnie 


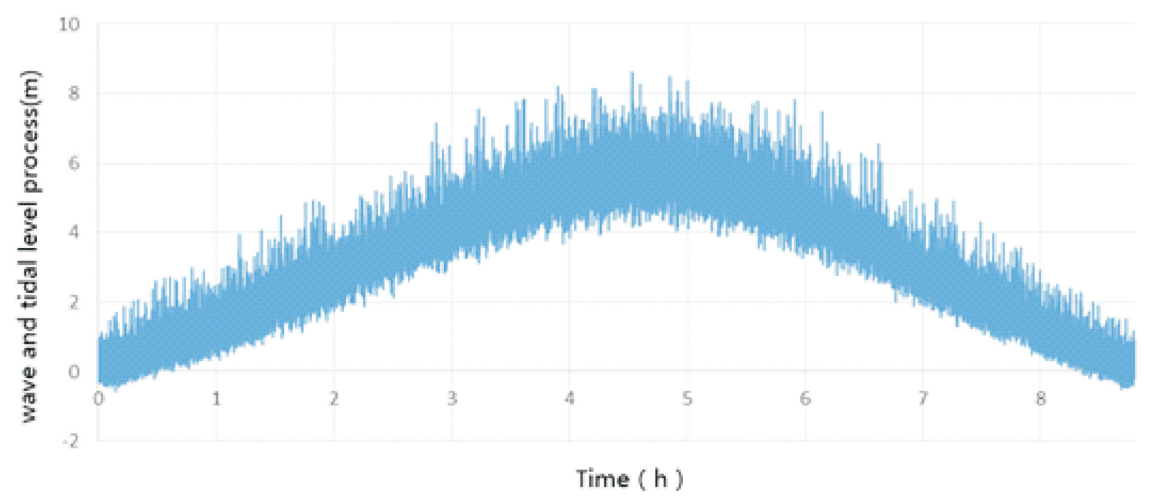

Fig. 9. The hydrograph of laboratory simulation of wave + tidal level changes

Shallow Water (NLSW) equation use a more efficient computational technique, but they have limitations due to hydrostatic pressure assumptions and for that reason have limited capabilities to describe the hydrodynamic processes in the swash zone.

One of the non-hydrostatic wave models is Simulating Waves till Shore (SWASH) developed by the Delft University of Technology, The Netherland, which can achieve reasonable overtopping for impervious dike under a tidewave coupled sea dynamics. The governing equations of SWASH are the non-hydrostatic, free-surface, non-linear shallow water equations, and optionally the equations for conservative transport of salinity, temperature and suspended sediment in one, two or three dimensions. SWASH can appropriately simulate surface waves and small-scale flows around hydraulic structures, waves approaching a beach, wave penetration in a harbor, flood waves in a river, complex changes to rapidly varied flows typically found in coastal flooding resulting from e.g. dike breaks, tsunamis, and flood waves.

In this study numerical simulations were carried out with SWASH (version 5.01). The physical model layouts described in Section 3.1 were reproduced in the SWASH numerical domain. The upstream boundary of the numerical model was $186 \mathrm{~m}$ ahead of the toe of the seawall, with the attempt to weak the reflection wave caused by the seawall. The total length of the numerical model domain from the upstream boundary to the end of the seawall was set to $200 \mathrm{~m}$. The grid size in the X-direction was set as $0.02 \mathrm{~m}$. The model was run with one layer in the vertical direction since the kd value was less than 3 , indicating that the estimated phase velocity error is insignificant. The time series of water surface elevation was obtained from the wave gauge before the 
dike was put in the flume. The incident wave time series was prescribed at the wave boundary in the numerical model with a weakly reflective boundary condition. A Sommerfeld radiation condition and sponge layer were applied at the downstream end of the numerical domain in order to minimize the effect of the reflection. A still water level was applied as the initial condition for all numerical models tests. The numerical time step was automatically changed during SWASH calculations to satisfy the Courant-Friedrichs-Lewy (CFL) condition. A Manning coefficient of $n=0.012 \mathrm{~s} / \mathrm{m}^{1 / 3}$ was adopted for the numerical simulation.

In the numerical model a time series of overtopping layer thickness $h(t)$, and overtopping velocity $u(t)$ on the sea dike or on top of the wave wall were extracted at the crest point. Then the overtopping discharge $Q(t)$ per unit length was calculated as the result of overtopping layer thickness and overtopping velocity. The free surface elevation, overtopping layer thickness and instantaneous overtopping discharge at a certain period of the typhoon development (water level) are plotted in Fig. 10.
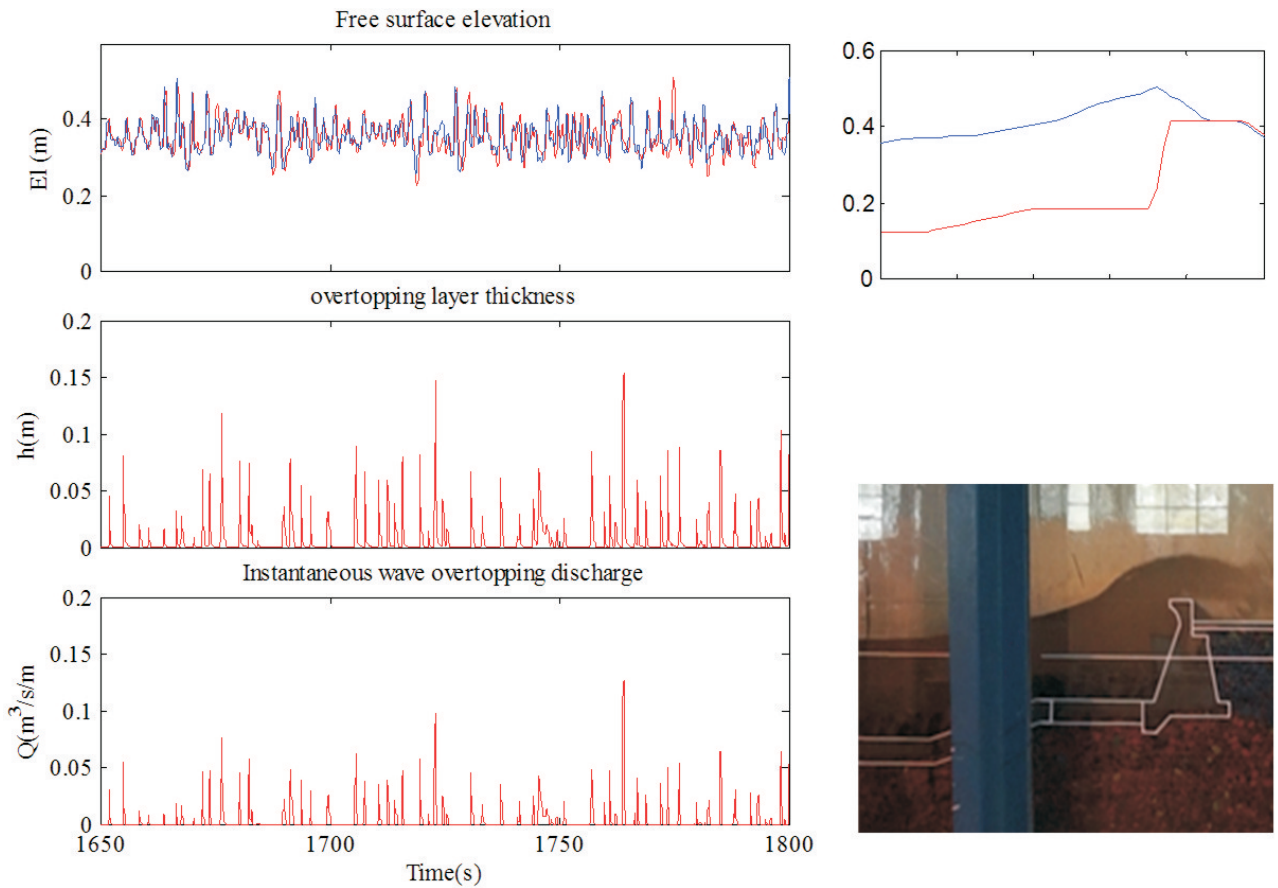

Fig. 10. Measured (blue line) and computed (red line) free surface elevation, overtopping layer thickness, instantaneous overtopping discharge at the prototype water level $5.01 \mathrm{~m}$ 
To understand the ability of the numerical model to resolve single intense overtopping events, the water surface elevation predicted by the numerical model in front of the sea dike is compared qualitatively using video images from the physical model, right panel in Fig. 10. The results show that when the tide level rises, the amount of overtopping discharge increases gradually. Generally, the numerical model gives reasonable results compared to the physical model.

\section{CONCLUSIONS}

Two cases of application of the integrated approach to modelling and study coastal flooding in coastal urban and estuarine area are tested and discussed in this paper. Respectively, two different tools were used for numerical simulation of physical processes.

MIKE 21 (MIKE FLOOD) numerical tool for simulation of inundation in urbanized coastal region of Bulgaria with complex topography and bathymetry was used in first case. On the basis of the field measurements and processed geodetic data a DEM with high resolution was built. The results obtained by numerical modeling of compound flooding in study area and the provided statistical \& field observation data are in good agreement that gives reason to use this approach when developing coastal flood protection projects.

Another variant of integrated approach has been demonstrated to study overtopping of the sea dike in coastal region in China under compound impact of sea level variation (tide and storm surge) and waves using phase-resolving model SWASH and physical model test in wave flume. Numerical results indicated that using a phase resolving numerical model could provide the wave overtopping which compared well with the physical model tests.

The integration of physical and numerical modelling (and where appropriate verification with data from field measurements) can provide a comprehensive approach to achieving a reliable prediction for flooding in areas with complex topography and bathymetry, as well as to deliver essential information to decision makers for flood risk management.

\section{ACKNOWLEDGEMENTS}

The authors express their sincere acknowledgements to National Science Fund of Bulgaria (NSFB) and the Ministry of Science and Technology of the People's Republic of China (MST PRC) for their financial support of this study within the framework of a joint project - Contract DNTS/01/12/2016 on the Agreement for Bilateral Scientific Cooperation. 


\section{REFERENCES}

[1] J. Sutherland And S. L. Barfuss, Composite Modelling: Combining Physical and Numerical Models HRPP Report 500, HR Wallingford, in: $34^{\text {th }}$ IAHR World Congress, Brisbane, Australia, June 2011, p. 9.

[2] V. Penchev, J. Pan, P. Penchev, D. Jia, Sh. Shukrieva, and Y. Wang, Composite Modelling of Flooding in Uneven Coastal \& Estuarine Areas, in: Proceedings of the $7^{\text {th }}$ Int. Conference SCACR, Florence, Italy, 2015.

[3] D. Kostichkova, Z. Belberov, E. Trifonova, and D. Grudeva, Maximum Sea Levels in Bourgas Bay, Physics of the Sea, Varna (2001) 3 (in Bulgarian).

Received April 19, 2021

Engineering Sciences, LVIII, 2021, No. 3 